\title{
PROTAGONISMO DE MULHERES INDÍGENAS NO ESPAÇO DE PODER: RESISTÊNCIA E SUPERAÇÃO
}

\author{
Danielly Coletti Duarte ${ }^{1}$
}

\begin{abstract}
RESUMO: O objetivo deste artigo é analisar a inserção da mulher indígena de etnia Terena no espaço de poder e tomada de decisão, no município de Campo Grande - MS. Ao atacar o problema da inserção, que pode ser marginal ou protagonista, das indígenas nestes espaços institucionais, sob o viés da Antropologia Feminista, fica em evidência a necessidade de maior participação feminina nestas áreas. Perspectiva possibilitada mediante a pesquisa de campo com uma liderança Terena. Este trabalho apresenta sua relevância ao destacar o sujeito feminino e étnico atuando nas esferas de poder, é um estudo inovador com o intuito de ampliar a bibliografia dentro da temática local.
\end{abstract}

Palavras-chave: Mulher indígena. Participação política. Políticas Públicas.

NHE'E BYKY: ko artigo'pe jahechakua'ata avá kuña Terena mba'eapohára pu'aka hendá'pe, Campo Grande'pe/MS. Sapuámi opyta okape ou mba'eapohára. Upeicha ko tekoteve ñemoiveva pu'aka hendá'pe, ojekua'á kuña tenondeta kuera.

Ayvu nhe'e: Avá kuña. Política tembiapo. Políticas Públicas.

ABSTRACT: Statement of purposes to analyze the indigenous woman's of etnia Terena insert in the space of power and socket of decision, in the district of Campo Grande - MS. When attacking the problem of the insert, that can be marginal or protagonist, of the natives in these institutional spaces, under the inclination of the Feminist Anthropology, is in evidences the need of larger feminine participation in these areas. Perspective made possible by the field research with a leadership Terena. This work presents your relevance when detaching the feminine and ethical subject acting in the spheres of power, it is an innovative study with the intention of enlarging the bibliography inside of the local theme.

Keywords: Indigenous woman. Political participation. Public politics.

\footnotetext{
${ }^{1}$ Especialista em Antropologia e história dos povos indígenas, pela Universidade Federal de Mato Grosso do Sul - UFMS; bacharela em Relações Internacionais, pela Universidade Federal da Grande Dourados - UFGD. Endereço Eletrônico: dnycoletti@ gmail.com.
} 
RESUMEN: El objetivo de este artículo es análisis de la introducción de la mujer indígena de etnia Terena en el espacio de poder y tomada de decisión, en la ciudad de Campo Grande MS. Al atacar el problema de la introducción, que puede ser marginal o protagonista, de las indígenas en estos espacios institucionales, bajo la inclinación de la Antropología Feminista, hay en pruebas la necesidad de la participación femenina más grande en estas áreas. La perspectiva hizo posible por medio del trabajo de campaña con un mando Terena. Este trabajo presenta su importancia separando la interpretación sustancial femenina y ética en las esferas de poder, es un estudio innovador con la intención de ampliar la bibliografía dentro del tema local.

Palabras Clave: Mujeres indígenas. Participación política. Política pública.

\section{Introdução}

A inserção e protagonismo em âmbito municipal, de lideranças indígenas nos espaços de poder permeia a vida das mulheres indígenas do município de Campo Grande - MS. A carência de bibliografias que envolvam estudo do desempenho da mulher indígena em seus trânsitos nas esferas de decisão no mundo ocidental fomentou este estudo, que se desenvolve sob uma perspectiva feminista, tendo como objeto a mulher indígena sul-mato-grossense da etnia Terena dentro dos espaços de poder político da esfera municipal de Campo Grande, sob a luz do arcabouço teórico antropológico-feminista.

As leituras da Antropologia Feminista estabelecem o ponto de partida da dupla condição de invisibilidade da mulher indígena Terena, enquanto minoria, indígena e mulher, na esfera política global do mundo ocidental, que é uma condição de submissão histórica de invisibilidade.

A linha paradoxal das transformações da realidade social, que possivelmente ocorre com a inserção da mulher indígena no espaço público de poder, aponta que ao percorrermos as representações da mulher indígena é imperativo que nos deparemos com acúmulos de negação de direitos, quanto da sua identidade indígena, substanciado pela própria condição feminina na civilização ocidental, à qual ser mulher é ocupar uma posição na estrutura social de segunda categoria. Assim como questionam as intelectuais feministas ocidentais, desde os primeiros passos da humanidade ocidental como há destacado Beauvoir, Safiotti, Rubin, entre outros importantes destaques, na literatura feminista.

Para a intersecção entre feminismo e antropologia, Marilyn Strathern (2009) define que a relação entre esses dois mundos de saberes apresentam divergências, no sentido que, enquanto o feminismo "busca" entender a condição de vida das mulheres mediante algumas transformações da realidade social, a antropologia procura explicar a origem do assujeitamento da mulher pela sociedade patriarcal eurocentrada (BONETTI, 2009). 
Em paralelo, existe a ação constante dos povos indígenas em mobilizar recursos próprios para travar contato com a sociedade. Em suma, procura-se demonstrar que faz parte da racionalidade indígena a leitura do mundo ocidental e ainda mais, a ação dentro das suas estruturas complexas. Todavia, porém, que guardam as proporções do agir dentro da conformidade dos interesses que não são do mundo dos 'brancos', mas que fazem jus a interesses próprios de seu modo de interpretar o mundo, isto é, fazem parte do seu ethos cultural e da sua etnicidade.

O segundo aspecto interessante a destacar, é evidenciar a questão da mobilidade das populações indígenas pelo território de Mato Grosso do Sul, tendo como ponto crucial o deslocamento das aldeias no interior do estado para a vida urbana da cidade grande, como é exemplo das várias famílias que transitam dos seus lugares originários e ancestrais, para a capital do estado. $\mathrm{O}$ intento desta perspectiva é perceber a confluência de interesses pertinente às comunidades indígenas em criar parâmetros de ação política, por meio de conquistas de espaços de decisão importantes para o seu território, sua cultura e sobrevivência de suas comunidades, mesmo tendo um arcabouço de entraves ao desenvolvimento de suas perspectivas étnicas de civilização e uma possível prosperidade de seus modos de vida.

Amparada por essa questão, a demanda preliminar dessa pesquisa foi a de analisar sob que aspectos são pautados as políticas públicas e ações afirmativas para os povos originários. Pois partindo dessa premissa foi que se construiu a reflexão sobre o contexto antropológico e sociológico acerca da representação e inserção da mulher indígena nos espaços públicos de poder. Uma vez que, é a política institucional abre algumas brechas que lhe são úteis à sustentação das estratégias de empoderamento subjacentes. Essa indagação foi, portanto, o ponto inicial deste trabalho de pesquisa.

Nesse caso, avaliamos a trajetória de uma dessas mulheres lideranças indígenas, que participa no espaço de poder, na capital do estado, em Campo Grande à luz da transitoriedade entre modos de ser que se inter-relacionam. A ideia principal do estudo é conciliar dinâmicas que aparentemente estão representadas por quadros divergentes, ou seja, os meios políticos institucionais da sociedade que estão delimitados aos espaços urbanos e etnocêntricos, acrescentando um olhar da etnopolítica ou, a ação centrada nas alianças interculturais que são constitutivas das comunidades indígenas. Por quanto seja, queremos procurar uma aproximação que comporte um ajustamento entre essas duas linguagens políticas que caminham em ritmos divergentes. Mas, que na realidade são complementares, já que o sujeito indígena faz parte desses dois mundos, simultaneamente. 


\section{A importância da mulher indígena à luz da antropologia feminista e da perspectiva de gênero}

O que se pretende nesta proposta é defender a potencialidade da Antropologia Feminista para explicação do processo de inserção (ou não) das mulheres indígenas nas agências de poder e na tomada de decisão, de forma a explicar as potencialidades das políticas públicas e ações afirmativas levantadas e defendidas pelas mulheres indígenas para a transformação de sua realidade social. Afinal, a falta de efetividade em programas voltados aos povos indígenas é reflexo da inoperância de políticas públicas paras os mesmos e como consequência desta negligência, as condições de vida desta população específica tornam-se precárias.

Afinal, como Oliveira Filho (1999, p.118) discorre:

Os direitos indígenas não decorrem de uma condição de primitividade ou de pureza cultural a ser comprovada nos índios e coletividades indígenas atuais, mas sim do reconhecimento pelo Estado brasileiro de sua condição de descendentes da população autóctone.

Haja vista, a construção de políticas assistencialistas é insuficiente para que haja o reconhecimento da cultura e a história dos povos indígenas, que carecem do direito, do poder de fala, principalmente no que se refere: políticas públicas para promoção da identidade e dignidade dos cidadãos indígenas brasileiros. Para além das medidas estatais, o que se apresenta como preocupante e urgente é a falta de uma contenção da violência institucional por parte do Estado, quando este ignora a necessidade urgente da construção de políticas públicas e ações afirmativas pela própria comunidade indígena. De forma a garantir uma vida digna aos cidadãos indígenas deste estado nacional. Somente desse modo evitaremos a extinção de vidas e, por sua vez, da tradição e da cultura dos povos ancestrais nos espaços que hoje temos como urbanizados e segregatórios, alçado pela filosofia da propriedade privada e pelo status que separam ricos e pobres.

Cabe notar, que por serem quantitativamente relevantes no quadro eleitoral, os povos indígenas são considerados disputa para a conquista de votos, no momento das promessas político-partidárias, mas e depois? São ignorados e relegados à margem da sociedade, sãolhes cerceados espaços sendo garantidas poucas oportunidades de participação e autonomia. Já que o tratamento político para o segmento social indígena é de pouca ou pequena eficácia e feita de forma assistencialista, isso por conta, de acordo com a assistente social Elisângela Candelária (2017), de uma intencionalidade para que não se cumpra os direitos dos povos indígenas evitando assim o direito ao acesso às suas Terras, por exemplo. 
Por tudo isso, a inserção, em âmbito municipal, de lideranças indígenas nos espaços de poder e o destaque para o seu protagonismo se mostra de relevância crucial para compreender as estratégias de confronto e ou contorno aos entraves de sua participação e destaque da agência deste sujeito na ordem política da sociedade que tenta cercear o seu direito de participação no cotidiano das cidades. Destacaremos aqui esse trâmite de ação política, por meio da ação da mulher indígena nos espaços de poder.

A Antropologia Feminista surge, pode-se dizer, como um estudo de gênero, por meio do interesse de estudos específicos feministas dentro da antropologia nos anos 70 (STRATHERN, 2009) marcando o surgimento da crítica social acerca dos domínios do patriarcado e a partir dessa crítica surge o conceito de gênero. Incitando, deste modo, no início da década de 1980, a reflexão de mulheres intelectuais de forma que trouxesse à tona a diferenciação no tratamento e as desigualdades nos diferentes âmbitos da vida, fossem eles: econômico, social e político, entre outros. Temos então que, o conceito de gênero passa a ser acrescentado à categoria classe social, complementando a mesma de forma que tentasse coibir a opressão em suas diferentes formas na história da sociedade quando a mulher, até então, é posta como coadjuvante. Surge desse modo, uma nova teoria na tentativa de se criar uma nova ciência mediante a inclusão da subjetividade e da concretude como categorias epistemológicas juntamente com a objetividade e a racionalidade (MURARO, 2001). A subjetividade inaugura essa nova ciência que objetiva, por meio do enriquecimento do conhecimento, uma ciência libertadora que pudesse modificar a conotação do poder opressor advindo do sistema patriarcal. Haja vista que, a sociedade se fez compreendida por uma homogeneidade enquanto que as grandes diferenças e complexidades, que de fato ocorrem em nosso cotidiano, fossem ignoradas. Portanto, a inserção da mulher como sujeito na história tem o poder modificador nas ciências, nas estruturas da força de trabalho, na administração do Estado e do mercado econômico. (MURARO, 2001, p.7,8 e 9).

Joan Scott, por sua vez, levanta duas reflexões quanto ao conceito de gênero: a) que foi construído por intermédio das relações sociais pautado nas diferenças anatômicas entre os sexos e b) que estabelece o primeiro significado das relações de poder (SCOTT, 1995, p.21). Deste modo, a relação entre homens e mulheres está baseada na reação de poder de um sobre o outro, de forma a estabelecer limites inferiores às mulheres na sociedade.

E dentro dessa escala as mulheres indígenas ficam em posição ainda de maior vulnerabilidade em relação às demais. Ressaltando que, a história corrobora com a inferiorização, digamos assim, da população indígena desde as classes escolares à vivência 
prática quando, por exemplo, não fornece a devida importância aos conhecimentos, culturas e hábitos indígenas incluindo as sabedorias acerca do corpo e sexualidade da mulher naturalizados na cultura ocidental, no sentido de que, de modo geral, pouco se reconhece as ações cotidianas cuja matriz veio dos povos indígenas.

A antropologia produz no indivíduo o poder do pensar por meio de dados interculturais (STRATHERN, 2009) que influem em toda sociedade independente de gênero (classe, etnia, religião, entre outros) colaborando, entre outros, para a explicação da história e para a manutenção de cultura por meio da análise da origem. Isso posto, a Antropologia Feminista ocorre, na década de 1970, por meio da Antropologia da Mulher que passa a questionar e refletir acerca do posicionamento da mulher nas produções etnográficas. Portanto, Alinne Bonetti caracteriza como fase inicial a teorização sobre a opressão feminina, que assumia em caráter universal, de acordo com a formulação das questões norteadoras das pesquisas de então (BONETTI, 2009). Essa fase buscava analisar principalmente acerca das vítimas oprimidas de cada sociedade e como a opressão ocorria. Posteriormente, o enfoque passa a ser sobre a organização de cada sociedade sobre os valores de gênero e como suas estruturas influem ou não em desigualdades de gênero dentro da mesma, de forma que a etnografia revela as complexidades de gênero e, portanto, o ponto principal nesta fase foi analisar a relação entre as convenções e práticas que, segundo Henrietta Moore (1994), apontavam para a desontologização do gênero e para o desempenho dos seus atributos. (BONETTI, 2009). Já a terceira fase da Antropologia Feminista passa a ter como enfoque a interseccionalidade de gênero e poder, que se espalha de forma a constituir o mundo social. (BONETTI, 2009, p.106-08). É uma vertente, segundo BONETTI (2009), da Antropologia estadunidense que apresenta orçamentos próprios, ou seja, com incentivos para a pesquisa. Essa vertente de acordo com Cristiane Lasmar, em "Mulheres Indígenas: representações", versa que: [...] os anos 70 e 80 distinguiram-se por uma efervescência teórica bastante significativa nos estudos de gênero, mas antropólogas feministas puderam tirar pouco proveito da realidade etnográfica das sociedades indígenas da Amazônia para a construção de seus modelos analíticos (LASMAR, 1999).

O mesmo pode ser afirmado em Mato Grosso do Sul. Logo, faltam subsídios no que se concerne às representações das mulheres indígenas no segundo estado com o maior quantitativo populacional indígena. O que, por sua vez, representa uma enorme lacuna na etnografia e história das mulheres indígenas dentro da antropologia feminista em contexto nacional, isso se justifica no fato de que a Antropologia Feminista ainda passa por um 
processo de construção, como afirma Alinne Bonetti em "Etnografia, gênero e poder: Antropologia Feminista em ação".

A Antropologia Feminista, pautada na etnografia crítica, é considerada, portanto, uma proposta de estudo teórico voltada, principalmente, para a união entre a análise das relações de poder e suas práticas juntamente com a perspectiva subalterna, como afirma Sherry Ortner (1996), por meio do modelo denominado "jogos sérios" em que o poder e as desigualdades, sempre, estão presentes na vida cotidiana.

A autora coloca a teoria da prática como prioritária para o entendimento das complexidades presentes na vida social, essa teoria deve ser pautada pelo viés "feminista, minoritário, pós-colonial e subalterno" dando atenção ao agente da ação e como este (re)produzirá as relações de poder na prática. Ortner (1996) segue afirmando que a união da teoria e da prática com a perspectiva daquela que é subalternizada, faz com que se pense nas relações de dominação e de poder justapostas com a intenção do ator. Isto permitirá compreender mais adequadamente a posição da mulher dentro das sociedades e como reverter a situação de inferioridade. Logo, o estudo de campo nos possibilita essa compreensão. Inferiu-se, por exemplo, a enorme força da mulher indígena dentro de suas aldeias e comunidades mesmo deixadas à margem, mesmo sem expressar seus sentimentos. Pelo motivo de que:

[...] a mulher é provedora, a mulher é que vai lá e trabalha com a Terra, a mulher que vai lá e traz a mercadoria para ser vendida para o comércio, para comercializar. Então, na verdade, a mulher indígena também ela é empresaria nata, eu acredito nisso, porque ela que sustenta sua família, ela provê tudo para tua família e não é reconhecida. Tanto pela sociedade purutuia e não indígena, quanto para a sociedade indígena também. Porque, dentro da aldeia ela não participa das reuniões, é raro as mulheres indígenas participarem das reuniões, porém é ela que decide. Porque, quando termina a reunião os homens, geralmente, vão para casa e perguntam se qual a decisão tomar e na verdade elas decidem, mas elas não podem aparecer (CANDELÁRIA, 2017).

Segundo Marilyn Strathern (2009) na teoria feminista bem como na antropologia busca-se compreender a essência da diferença por meio do método comparativo e da prática investigativa e o primeiro passo para isso se dá por meio da interpretação, e enfatização do significado, da experiência que, por sua vez, é resultado do surgimento da consciência.

Levantar a reflexão acerca da inserção das mulheres indígenas no campo político significa, também, analisar além de suas estruturas organizacionais, suas organizações políticas nos movimentos sociais de instâncias nacionais e internacionais, de forma que possibilite a disseminação de suas práticas político culturais mediante o estudo da questão 
indígena partindo das perspectivas de gênero e etnia. A questão de gênero é permeada pela diferença entre um e outro, sendo as mulheres classificadas como o outro, como versa Marilyn Strathern (2009):

[...] a redescoberta constante de que as mulheres são o Outro na consideração dos homens, relembra às mulheres de que elas devem ver os homens como o Outro da relação de si mesmas. Criar um espaço para a mulher converteu em um espaço para o eu e a experiência se converteu em um instrumento para o conhecimento do eu. Então para a construção do eu feminista, é necessário o Outro não-feminista. O Outro é concebido como "patriarcado" e as instituições e as pessoas que representam a dominação masculina são simplesmente, de maneira frequente, concretizadas pelo termo "homens". Dado que o objetivo é restaurar à subjetividade um eu dominado pelo Outro, não podem haver experiências compartilhadas com pessoas que permanecem no Outro. (STRATHERN, 2009, p. 97 e 98).

Sobre isso, mediante a pesquisa de campo, pudemos captar o eu e o outro dentro da sociedade indígena no momento em que a mulher indígena é quem fica com "a criança, é ela que fica com o trabalho pesado e os homens geralmente vão [...] buscar essas políticas públicas pra dentro das aldeias. Mas que geralmente não chegam até lá" (CANDELÁRIA, 2017). O que denota uma relação complexa e intrínseca entre o eu e o outro, homens e mulheres, na sociedade indígena. Por um lado, a mulher ocupando a posição do outro, a posição subalterna, na divisão sexual do trabalho, sendo este o trabalho do âmbito privado. Enquanto que o homem, em posição de dominador, se ocupa em melhorar a qualidade de vida da comunidade, ligada às atividades de âmbito público. De outro lado, e neste ponto entra a complexidade, por meio da pesquisa de campo, constatou-se que, em verdade, a mulher indígena é quem desenha o cenário estratégico da ação prática de dada decisão ou ação prática.

Logo, pautar a Antropologia Feminista significa analisar a origem de dada situação social e analisar quais são seus possíveis cenários. Isso posto, pensar acerca de gênero e das relações de poder que o envolve, situadas no âmbito político-feminista e na inserção de mulheres indígenas nos espaços de poder no município de Campo Grande orientados pela Antropologia Feminista, foi o que motivou a presente pesquisa teórico-metodológica.

\section{A migração para a cidade: criação de políticas públicas e ações afirmativas para os povos indígenas em Campo Grande - $\mathrm{MS}^{2}$}

\footnotetext{
${ }^{2} \mathrm{O}$ estado de Mato Grosso do Sul - MS apresenta o segundo maior índice populacional de população indígena, estimado em 73.295 mil indivíduos. Entre estes se destacam as seguintes etnias: Terena, Kaiowá, Guarani Ñhandeva, Guató, Kadiwéu, Kinikinau, Ofaié, Kamba e Atikum. É importante salientar que: o presente artigo terá como foco da pesquisa as mulheres indígenas da etnia Terena residentes em Campo Grande, capital do
} 
A questão da mobilidade dos povos indígenas por todo o território de Campo Grande MS tem início durante a década de 1960, sendo intensificada nos anos de 1990. O processo de deslocamento das aldeias do interior do estado, local de origem, para os centros urbanos. Neste texto analisaremos que, esse deslocamento, mais especificamente para Campo Grande, tiveram fatores diversos. Entre os motivos nota-se a busca por melhores condições de vida representadas pelo acesso ao mercado de trabalho, acesso à saúde e acesso à educação. Somadas a algumas problemáticas, tais quais: trabalho escravo, desapropriação e a não regulamentação de terras o que, por sua vez, foi responsável pelo êxodo indígena de modo massivo e acarreta até hoje violências sistemáticas.

A mobilização indígena está, sobretudo, pautada em suas necessidades específicas. Por exemplo, tais questões inseridas na estratégia de articulação do povo Terena, vislumbra a tentativa de garantir reconhecimento, direitos e acessos, incluindo aqui, nas agências de poder e tomada de decisão, por meio da participação, inicial, em conselhos municipais e em movimentos sociais. E, foi após o movimento migratório que houve o processo de inserção das mulheres indígenas ${ }^{3}$ nos espaços de poder, que embora represente algum avanço, persistem divergências entre a perspectiva da sociedade indígena e a sociedade ocidental.

Os povos indígenas pensam e lidam de modo distinto aos não índios com a política, por serem pautados por códigos e símbolos morais que fazem jus ao seu modo de vida originário autóctone. Portanto, ainda que em contexto urbano as ações e representações se articulam em caracteres de diferentes aspectos no âmbito das motivações e interesses, pois tais interesses de ações políticas se remetem em prol da sua cultura. Em afirmação dessa distinção temos que, como já bem exposto por Eduardo Nunes (2010), a imagem do índio é categoricamente inferiorizada e estigmatizada em comparação ao não índio, e esta é uma

estado de Mato Grosso do Sul. Os Terena, povo de língua Aruák, hodiernamente habitam Terras indígenas distribuídas em diversas aldeias ou em regiões de retomadas de alguns municípios sul-mato-grossenses, tais quais: Anastácio, Aquidauana, Campo Grande, Dourados, Dois Irmãos do Buriti, Miranda, Nioaque, Rochedo e Sidrolândia. As maiores reservas indígenas do povo Terena estão no município de Dourados fundada, no ano de 1915, pelo Serviço de Proteção ao Índio - SPI e em Campo Grande, cuja população Terena está distribuída em 5 (cinco) aldeias ou comunidades urbanas. Essas comunidades estão localizadas em bairro periféricos, são eles: bairro Tiradentes com a Aldeia Marçal de Souza; bairro Nova Lima com as Comunidades Água Bonita e Tarsila do Amaral; bairro Jardim Noroeste com a Aldeia Urbana Darcy Ribeiro; e no Núcleo Industrial Indubrasil com a Aldeia indígena do Núcleo Industrial. Essas comunidades formam conjuntos habitacionais criados pela Prefeitura Municipal de Campo Grande - PMCG em parceria com a Agência Municipal de Habitação de Campo Grande - EMHA e com a Agência de Habitação Popular de Mato Grosso do Sul -AGEHAB (SILVA e BERNADELLI, 2016). Cabe ressaltar que para além das aldeias urbanas citadas, alguns indígenas Terena vivem nos bairros Jardim Carioca, Guanandi, São Jorge da Lagoa e Santa Mônica.

\footnotetext{
${ }^{4}$ Talvez uma hipótese seja que junto a essa migração tenha um vetor adicional, o processo de monetarização em que as mulheres indígenas se destacam pela venda de produtos agrícolas e artesanais.
} 
chave em constante atrito no modo de perceber a sociabilidade do sujeito indígena na esfera social da sociedade ocidental. Para Eduardo Nunes (2010), o processo migratório do índio ao ambiente urbano está diretamente vinculado a questão das essências, para o autor a concepção de índios em contexto urbano é tida como uma "contradição de termos".

O selvagem fora da selva, (quase) camuflado entre prédios, é pensado como um indivíduo deslocado, fora de seu próprio mundo, em contradição com a essência de seu ser. Um dos problemas envolvidos aqui [...] é a certa teoria de mudança cultural, que toma a transformação como um processo de tornar-se diferente de si próprio e, como consequência, igual a outrem, deixando, assim, de ser quem se é (NUNES, 2010, p.16).

Nunes, desse ponto de vista, afirma que a urbanidade é o modo de vida. Portanto, se o ambiente em que vivem são os campos, há a falácia de que suas Terras ${ }^{4}$ não são produtivas. Com a alternância do ambiente de origem para a cidade, o índio é mais uma vez marginalizado. O que, por sua vez, denota a falta de conhecimento em relação a cultura indígena, e ele continua, aos olhos dos não-índios, na conotação do não serviente. Ele não "serve" para o mercado de trabalho, a não ser o trabalho braçal; ele não "serve" para nada além de servir ao outro, ao branco, mais precisamente. E cabe aqui, destacar a resistência e rebeldia dos povos originários diante de todo contexto social de desigualdade em que vivem. Pois, os Terena principalmente, agem de acordo com seus interesses, necessidades e interpretações, dialogando para isso, muito bem, com a sociedade não-índia, sem, dessa forma, pertencer a mesma. Ou seja, pertence ao ethos Terena a troca e a aproximação com a sociedade não-índia para consecução de interesses viáveis à sobrevivência, bem como, para manutenção e prosperidade de sua etnia.

A inferiorização sofrida pelos povos indígenas em relação aos não índios, faz parte da construção social, ainda, presente na sociedade pós-moderna. Tal como aponta Juliana Melo (2013) em relação a existência de duas concepções opostas: o "mundo dos brancos", representada pela modernidade contemplando o indivíduo não coletivo e ao "mundo dos índios" e as aldeias; e o isolamento; e a coletividade, representada pela natureza. E ao analisar o nosso contexto de sociedade, levando em consideração que tudo o que somos e o que fazemos vem de uma construção social e, portanto, os diferentes assim os são pela existência de inúmeras culturas distintas entre si, porém que se assemelham a macro divisão,

\footnotetext{
${ }^{4}$ A palavra Terra está representada com letra maiúscula para lembrarmo-nos da concepção simbólica que a MãeTerra representa aos povos nativos. Não serão terras produtivas, nem mercadorias, como se tratadas pelas mãos dos não índios, mais precisamente pelas mãos dos grandes latifundiários. Há que se questionar, portanto, o sentido de produção para os não índios cujas Terras produzem vida, símbolo, significado, entre outros.
} 
digamos assim, classificadas em "cultura ocidental" e "culturas subalternas". Portanto, nos referimos aqui ao conceito de multiculturalidade 5 .

Deste modo, a crença na inferioridade e incapacidade do índio na realização de atividades comuns aos brancos simboliza, como afirma Juliana Melo (2013),que embora haja o (pré) conceito entorno dos povos indígenas, os purutuias $^{6}$ não percebem que estes, os índios, estão há tempos inseridos nas cidades e, para além disso, colaboram na construção do cotidiano urbano, apesar de injustamente serem percebidos como "anomalias"(Hall, 2005).

Essa percepção deturpada do indígena se deve a dois fatores principais, tais como: por um lado, o processo de construção social, e de outro, por falta de políticas públicas destinadas aos povos indígenas (como se não fizessem parte da clientela do Estado). Vista disso, são falhas estruturais homogeneizadas na qual o diferente não se enquadra. Decorrente disso, partem os (pré)ssupostos da discriminação do diferente.

Diante do exposto, nos indagamos: Onde estão os indígenas nos espaços de poder no município de Campo Grande? Quantos são? Desses, quantas mulheres estão inseridas nesse espaço? E principalmente, quem de fato elabora as políticas públicas para os povos indígenas? São os próprios índios? Ou majoritariamente os brancos controlam a pauta política indígena e suas demandas? Sabemos que as pautas e demandas indígenas em nossa sociedade, assim como a pauta das mulheres, estão em segundo plano nos governos e por mais que existam políticas públicas para os povos indígenas, estas se encontram, muitas vezes, marginalizadas, esquecidas, negadas.

Outro fator de destaque a ser pontuado a respeito da inserção do sujeito indígena em ambiente urbano e ocidental, faz referência a quem direciona as políticas públicas e ações afirmativas. No município de Campo Grande, citamos aqui, como ilustração desses contrassensos, o I Seminário de Direitos Humano \& Políticas Públicas para os Povos Indígenas em Contexto Urbano ${ }^{7}$.

Para tal seminário, lideranças indígenas foram “convidadas”. Contudo, ficou evidente ausência de representatividade indígena na mesa, na elaboração do plano, bem como, na

\footnotetext{
${ }^{5}$ Multiculturalidade ou diversidade cultural faz referência a culturas distintas convivendo integralmente na mesma sociedade. De forma que não causa danos a nenhuma em relação a outra. A multiculturalidade pode ocorrer mediante migração ou imigração.

${ }^{6}$ Refere-se ao não indígena, na língua Terena.

${ }^{7}$ Ocorrido, em 24 de abril de 2017, na Universidade Federal de Mato Grosso do Sul - UFMS, a estrutura do evento foi organizada, ou "colonizada", por parlamentares (não-índios) do município, juntamente com setores da prefeitura e da referida Universidade, a fim de que fosse construído o Plano de Política Indígena de Campo Grande- $M S$, todavia, com a ausência da autonomia indígena na construção do mesmo.
} 
manifestação própria de suas necessidades. Foi um evento de brancos políticos e acadêmicos para brancos, não pretendendo aqui desmerecer o evento. Mas, sim, levantar a indagação do por que a voz imperativa do branco exerce a dificuldade em calar-se para que seja feita a escutada das vozes e das perspectivas da comunidade indígena? Já que, tratou-se de um evento que com o intuito de discutir e elencar as necessidades prioritárias de dentro das comunidades indígenas de nossa capital. Temos como resultado crítico desta reunião que, em $1^{\mathrm{o}}$ lugar não foram os próprios indígenas protagonistas, de forma que o branco fosse seu ouvinte e ou parceiro na construção dessas políticas; em $2^{\circ}$ lugar, a escolha do local, sem ampla mobilização das comunidades, inviabilizou a maior presença de participantes indígena na discussão ${ }^{8}$. Um resultado que julgamos pertinente na construção da discussão includente dos indígenas, seria reuniões locais prévias dentro das aldeias urbanas e demais destacamentos que pudessem reunir também aqueles indígenas que residem na cidade, mas não se encontram reunidos nos 'bairros etnicizados'; outra visão que temos para fomentar a participação seria da mobilização geral dos participantes na plenária, com ampla divulgação do evento pela cidade, utilizando meios de comunicação abrangentes.

Portanto, o evento, em suma e de fato, não foi para os povos indígenas. E sobre isso, é urgente o convencimento por parte dos não índios que é um grande equívoco, mesmo que com "boas intenções", dizer o que é melhor ou não para com o outro, neste caso para os povos originários. Esse episódio, entre tantos outros, refletem a objetificação dos povos indígenas por políticos e população geral, pois imaginam reverter números em votos nos períodos de campanhas eleitorais. Porém, se de fato fossem construídas políticas públicas nenhuma comunidade periférica indígena, e isso reflete a invisibilidade dos povos indígenas, estaria carecida de demandas básicas, como saneamento, pavimentação, educação e saúde, por exemplo, e não dependeriam de medidas assistencialistas. Porque atualmente a política pública que ocorre nessas comunidades são encaradas de maneira geral e pejorativa o que, por sua vez, denota um fator paliativo e insignificante para a mudança da condição precária de vida.

\footnotetext{
${ }^{8}$ Haja vista que já que os locais habitados pelas comunidades indígenas em contexto urbano são as periferias e essas são afastadas do grande centro o que, por sua vez, gera inúmeras dificuldades de locomoção para os indígenas que moram longe da Universidade Federal de Mato Grosso do Sul, local onde o referido evento foi realizado.
} 
Outro destaque vindo das vivências de campo ocorreu durante o seminário Ancestralidade: mulher e sábios indígenas ${ }^{9}$, sendo este de total protagonismo dos povos indígenas. Porém o atual gestor do município ${ }^{10}$ levou o embaixador para conhecer a comunidade modelo, estruturada em função de visitas internacionais que o município mantém para salvaguardar a sua imagem de cidade interétnica inclusiva, a aldeia urbana Marçal de Souza. Representando um projeto de sucesso, essa comunidade da capital é reconhecida e, ao contrário das outras, acessada toda vez que querem escamotear a realidade dos nossos indígenas. Assim, são sufocadas as condições de necessidade e isolamento que ocorre nas demais comunidades. Como ocorre, por exemplo, na aldeia urbana Água Bonita, ou Indubrasil, acampamento indígena do Noroeste e Oiti, entre outros lugares que abrigam populações indígenas e que não são catalogadas sequer pelo estudo acadêmico. Deveria, então, o estado com o segundo maior quantitativo de população indígena ter comunidades tão carentes?

Em relação à comunidade modelo, a Aldeia Urbana Marçal de Souza apresenta dois marcos importantes. Além de ser a primeira do país a ser delimitada como área urbana, foi a primeira aldeia com uma cacique, ou cacica, a Sra Enir Bezerra da Silva ${ }^{11}$. Enir da Silva, Elisângela Candelária ${ }^{12}$, entre tantas outras indígenas, migraram ainda novas para os centros urbanos, motivadas pela "falta de acesso de políticas públicas para os indígenas nas aldeias" (CANDELÁRIA, 2017). Quando em contato com a vida urbana se depararam frustradas, pois a expectativa de melhoria na qualidade de vida não é atingida por viverem em situação de miséria, por sofrerem variados (pré) conceitos, entre outros.

O processo migratório, de acordo com Elisângela, faz com que as mulheres sofram caladas e quando essas têm a oportunidade de falar, "contam da sua vida amarga que foi

\footnotetext{
${ }^{9}$ Ocorrido nos dias 20 e 21 de março de 2017. O evento foi idealizado pelo Comitê Intertribal Memória e Ciência Indígena (ITC), com a Embaixada do Canadá como patrocinadora e com o apoio da Fundação Ueze Zahran e do Tribunal de Justiça de Mato Grosso do Sul.

${ }^{10}$ Marcos Marcello Trad, com mandato entre os anos de 2017 à 2020.

${ }^{11}$ Enir foi e é uma referência feminina por seus feitos na comunidade como, por exemplo, pela mobilização de famílias indígenas a ocuparem o espaço onde a referida comunidade foi construída; por sua luta na reconstrução da identidade indígena; por sua luta para conquista de direitos e dignidade, entre outros, significando um avanço para as mulheres indígenas de Campo Grande. Contudo, houve resistência dentro da própria comunidade para que Enir assumisse o posto de cacique, mesmo sendo eleita mediante voto secreto, porque era uma mulher.

${ }^{12}$ Elisângela Candelária é uma mulher indígena da etnia Terena, tem 43 anos, é formada em Serviço Social, pela Universidade Católica Dom Bosco - UCDB. Migrou para Campo Grande - MS aos 10 anos, à trabalho. Elisângela foi entrevistada durante a construção do presente artigo, pois se inseriu e atuou no espaço de poder levando melhorias para mulheres das comunidades indígenas, no município de Campo Grande, enquanto técnica da pasta de mulheres indígenas na Secretaria Municipal de Políticas para as Mulheres - SEMMU.
} 
chegar até ali [no centro urbano]" (CANDELÁRIA, 2017), deixar as Aldeias em busca de melhores oportunidades nas cidades e não atingir o intento fez com que "muitas delas caem em depressão e nem sabe que estão depressivas, não sabem disso. Então elas, elas continuam sofrendo. Sofriam na aldeia e aqui elas continuam sofrendo.” (CANDELÁRIA, 2017). Contudo, há resistência, rebeldia e, sobretudo, superação para o enfrentamento das adversidades da vida cotidiana, bem como, no enfrentamento ao paternalismo dentro das aldeias e dos (pré)conceitos sofridos.

Felizmente, existem lideranças, como Enir Bezerra, enérgicas, e que unem suas comunidades, que lutam por direitos e vida digna, empoderando outras mulheres por meio do fortalecimento interior e disseminação de suas sabedorias. Enir, por exemplo, acreditou que sua contribuição ocorreu por meio do encorajamento das mulheres indígenas provocando "com que se sentissem mais fortes" (SILVA, 2015). "Hoje elas participam mais, já discutem com igualdade com os homens, já dão opinião. Sempre dizendo que não estão ali para medir força, mas para somar.” (SILVA, 2015). Elisângela afirma, também, que ao migrarem para a cidade os indígenas não deixam de ser índios, mas perdem direitos garantidos, o que por sua vez, "tem sido a nossa luta, a nossa resistência para ter uma saúde pra mulher de qualidade, um acesso a educação, acesso a informação, acesso ao trabalho, um trabalho digno". (CANDELÁRIA, 2017). Ademais, a migração das aldeias para os centros urbanos oportunizou a inserção das mulheres indígenas nas agências de ações e tomada de poder por meio do incômodo causado pelas condições de desigualdade, denotando pequenas conquistas para as mulheres.

Deste modo, infere-se que os povos indígenas não são apáticos, sem história ou sem perspectiva, ao contrário, estão constantemente mobilizados para a manutenção de seus direitos visando, com isso, melhoria na qualidade de vida de seu povo. Compreende-se, também, que as mulheres indígenas embora estejam camufladas, fora dos assuntos acadêmicos, sob ausência de políticas públicas eficazes, se apresentam cada vez mais fortes, persistentes e participativas, seguindo o exemplo de Enir Bezerra da Silva, a primeira mulher cacique do Brasil, da primeira aldeia urbana do país.

\section{O espaço público de campo grande não falado sob a ótica da mulher indígena terena}

"De modo geral, o que se constata é que as mulheres são ainda quase que "invisíveis" para o indigenismo brasileiro, apesar dos avanços efetivados nos últimos anos, no Brasil, no tocante às políticas sociais" (VERDUM, 2008). Assim, foi substancial a compreensão do 
sistema de inserção de mulheres indígenas nas agências de ação e tomada de poder, no município de Campo Grande - MS, para que se tenha registrado esses pequenos avanços. Sob a perspectiva investigativa acerca da autonomia das(os) técnicas(os) e gestoras(es) indígenas firmados nesses espaços. Ou seja, ampliando o escopo da compreensão da estratégia de inserção de mulheres indígenas no espaço de poder, de maneira a compreender se, quando estabelecidos nesses locais, possuem autonomia gestora para a execução de suas atividades, fazendo referência a efetividade dos programas das políticas públicas para os povos indígenas. O que foi ocasionado mediante o levantamento teórico acerca das políticas públicas e ações afirmativas no intento de constatar se há a garantia, ao menos, de direitos básicos, tais quais: saneamento básico, moradia de qualidade, acesso à educação e ao trabalho digno.

A invisibilidade da mulher indígena traz em seu bojo, além da complexidade entre a relação do eu e do outro, a complexidade do que é viver em um sistema não estatal sob ampla influência do Estado. O antropólogo Pierre Clastres, afirma que nas sociedades estatais a estrutura político-administrativa é centralizada e especializada, de modo a garantir a ordem social lançando mão de recursos que podem ou não ser utilizados. Quando que, nas sociedades não estatais em sua estrutura organizativa não há a presença do Estado, assim como é o caso das sociedades indígenas. Portanto, no sistema não estatal indígena há um sistema de controle social próprio representado por caciques, por exemplo, entre outros modos de liderança e estruturação política (DE PAULA; VIANNA, 2011, p.15). E embora seja esse seu modo organizativo, os indígenas convivem também com o modelo estatal, haja vista que seus territórios são considerados da União, e quando em centros urbanos, estes ainda, respondem as diretrizes do Estado.

Logo, os povos indígenas habitantes dos centros urbanos, sob as diretrizes da sociedade Estatal dialoga com o não índio, sob base do conhecimento de seus direitos, no intuito de garantir a construção de políticas públicas de acordo com suas especificidades. Dada esta ação, se desencadeou por meio da migração para os centros urbanos o processo, gradual, de inserção indígena na política. Em síntese, percebe-se que esta inserção ocorre de duas formas: por intermédio da indicação de um representante por parte dos caciques e lideranças locais que, geralmente estão apoiados por governantes políticos. De outro, e o que acontece principalmente com as mulheres indígenas, a inserção ocorre inicialmente por meio da participação em conselhos e movimentos sociais e, posterior a isso, pela indicação de caciques e lideranças indígenas. 
Durante a pesquisa de campo foi observado que a sociedade indígena é, como afirma Elisângela Candelária (2017), "muito machista e isso as mulheres tem lutado"13 para mudar. Os homens indicam, em maioria, outros homens. Estes sendo capacitados ou não. Por conseguinte, as mulheres que detém maior nível de conhecimento e especialidade ficam à margem da sociedade Estatal e não estatal. Haja vista que embora disputem maiores espaços, as indicações e nomeações ocorrem em detrimento da decisão da cúpula de lideranças indígenas, digamos assim, ao invés da análise curricular, por exemplo, tanto por parte das lideranças indígenas, quanto por parte do governo. O que acarreta, por sua vez, uma série de outras reflexões como, por exemplo, se esse formato de escolha corrobora para a conjuntura periférica das comunidades urbanas de Campo Grande; se é falta de zelo, conhecimento ou assessoria para as escolhas dos representantes; se essas pequenas inserções são uma espécie de cota na política municipal; entre outras indagações.

À vista disso, a observação etnográfica mediante a perspectiva de uma liderança indígena, Elisângela Candelária, assegurou a construção fidedigna da participação indígena na política pública do município. Independente da quantidade, da funcionalidade e da efetividade, o que observaremos a seguir representa, para além de uma contribuição documental, um avanço para a sociedade indígena, que outrora foi escravizada e tutelada. Por outra perspectiva, além da evolução natural da humanidade, a inserção no espaço de poder tem como simbolismo dizer ao Estado que em relação as políticas indigenistas quem entende, são seus próprios sujeitos. Assim sendo, a antropologia e a história da inserção indígena nos espaços de poder, desenhada e narrada por uma mulher indígena, conduz "as mulheres no centro como objeto de pesquisa e como agente ativo no acúmulo do conhecimento" (STACEY \& THORNE, 1995 apud STRATHERN, 2009). Representando grandes rupturas e pequenos avanços históricos, em Âmbito privado e público ${ }^{14}$. O primeiro quando, por exemplo, uma mulher indígena se empodera e dissemina a força da mulher dentro de suas comunidades e aldeias revelando uma ruptura com os desdobramentos do patriarcado, como o paternalismo dentro da comunidade. E esse empoderamento se desloca, consequentemente,

\footnotetext{
13 Tradicionalmente a cultura/organização social advém da divisão sexual do trabalho. Logo, o surgimento de novas atividades, papéis e contextos a partir do contato com o não índio levam os povos indígenas a um novo passo, o de lidar com novos problemas. O contato com o não índio proporciona o aprendizado de boas e más práticas.

${ }^{14}$ Neste caso, o âmbito privado está representado pelas comunidades e aldeias urbanas e o âmbito público está representado pelas agências de poder e tomada de decisão, ambas configuradas no município de Campo Grande $-\mathrm{MS}$.
} 
para o âmbito privado no instante em que essas mulheres passam a interferir na construção do espaço político e organizacional.

Por intervenção da teoria antropológica feminista é possível analisar as estratégias e ações práticas das mulheres indígenas sob a conjuntura das relações de poder. Haja vista que a Antropologia Feminista versa acerca da compreensão dos "sistemas e valores de gênero e como tais sistemas implicam ou não em estruturas de desigualdade" dentro das sociedades (BONETTI, 2009, p. 107). O direcionamento prático de tal teoria demonstra que embora hajam sujeitos subalternos em relação aos valores de gênero nas sociedades indígenas, o que acarreta em estruturas de desigualdade, as mulheres indígenas iniciam um movimento de empoderamento, mediante a ampliação do conhecimento acerca de seus direitos em contato com movimentos sociais, como haja vista, inspiradas nos passos de Enir Bezerra da Silva, caso aqui apresentado.

Elisângela Candelária afirma que o despertar para a causa e efeito das opressões vivenciadas desde então tomaram nova perspectiva após o seu contato com a universidade e, em particular, com o curso que lhe atribuiu o título de assistente social. Alega que seu primeiro contato com a sociedade não índia foi muito "impactante", pois, a mesma não havia percebido o tamanho preconceito existente fora do contexto de trabalhadora operária ou braçal, atividades que estava acostumada a desempenhar desde, os dez anos, quando migrou para Campo Grande. Elisângela afirma que, ainda assim, a busca pelo conhecimento foi consubstancial para a alternância da perspectiva a cerca das opressões vivenciadas por ser mulher e indígena. A busca pelo conhecimento se tornou necessária, pela:

dificuldade mesmo que ser indígena para a sociedade urbana, ela nos cobra isso. Nos cobra títulos, nos cobra experiência de trabalho, conhecimento. Então isso fez com que eu cursasse a universidade, o curso de serviço social. E também, é pelo, porque nós, pra mudança mesmo de vida, pra um bem estar melhor, é (para um) crescimento intelectual pra ajudar também o meu povo porque, principalmente, as mulheres que são oprimidas dentro da comunidade. Então, o serviço social veio contribuir para a minha inserção no movimento indígena, no movimento social indígena. (CANDELÁRIA, 2017).

Elisângela também relata quanto a dicotomia entre a vida no campo e na cidade quando afirma que, por viverem em uma sociedade capitalista, os povos indígenas são cobrados constantemente em todos os âmbitos e, além disso, desejam adquirir, para si e para seus filhos, os bens materiais de consumo. Ao passo que nas reservas indígenas "a maioria das pessoas trabalham hoje para comer amanhã". Ou seja, o ethos indígena permanece no índio que migra, mas, este quando em ambiente que, de modo geral, apresenta hostilidade em relação ao "diferente", passa por transtornos diversos. 
No município de Campo Grande - MS o poder executivo conta com 21 órgãos ${ }^{15}$ divididos entre: secretarias, subsecretarias, agências e institutos municipais. Porém, como observado, por Elisângela Candelária, atualmente, em 2017, não há nenhuma mulher indígena inserida nessas agências.

A entrevistada menciona que sua inserção no espaço de poder ocorreu posteriormente a sua formação acadêmica e aos anos de militância no movimento indígena e de atuação em conselhos, tal qual o Conselho Municipal de Direitos Indígenas - CMDI. Quando inserida no espaço público de poder, Elisângela, atuou como técnica da Secretaria Municipal de Políticas para as Mulheres - SEMMU, coordenando a pasta de mulheres indígenas.

Além disso, segundo ela, foi possível vislumbrar a oportunidade de fazer chegar as políticas públicas e ações afirmativas para as mulheres indígenas residentes da capital, Campo Grande - MS. Sua experiência no setor público foi de trocas de conhecimentos com as demais técnicas da referida secretaria. Sendo enriquecedora, apesar das "dificuldades" no que se referiu ao método de aplicação das ações afirmativas, que eram sumariamente de "politicas assistencialistas", por conta de falta de recursos ou outras prioridades dentro da SEMMU.

Elisângela cita a presença de mulheres indígenas "de fibra, que lutam bastante" (CANDELÁRIA, 2017) ocupando os espaços de poder em diversos estados brasileiros como, Amazonas, Alagoas, Mato Grosso e, como já ocorreu, em Mato Grosso do Sul. Denotando pequenos avanços para os povos indígenas, em especial às mulheres indígenas, Contudo, infelizmente, ainda sem autonomia suficiente para alcançar os objetivos principais que é, justamente, "fazer política, pautar política pública afirmativa." (CANDELÁRIA, 2017) ao invés de promoverem políticas localizadas, "apagando um incêndio aqui ou ali" (CANDELÁRIA, 2017), as denominadas políticas assistencialistas. Logo, a entrevistada, levanta um questionamento importante "Como fazer com que, realmente, as políticas cheguem até as mulheres indígenas?" (CANDELÁRIA, 2017). Esse questionamento surge em meio à narrativa acerca do período em que esteve inserida no espaço de poder, como crítica a política adotada por e para os povos indígenas em contexto urbano. São contextos cuja prerrogativa, segundo a mesma, encontra-se pautada na tutela dos indígenas (CANDELÁRIA, 2017) que, em suma, formam "um estrago para a nossa população [...]. E isso nos trouxe para onde? [...] porque querendo ou não, é uma herança esperar acomodados"

${ }^{15}$ Disponível em: <http://transparencia.campogrande.ms.gov.br/orgaos/>. Acesso em: 10 jun 2017. 
(CANDELÁRIA, 2017). A impressão de acomodação que se origina no processo da colonização e ainda atrapalha a vida dos indígenas, segundo Elisângela, é consequência da violência do processo histórico de colonização e posteriormente de intervenção direta do Estado, mediante o Serviço de Proteção ao Índio - SPI sobre a estrutura organizativa dos povos originários. Culminando, por fim, em um ciclo entre as políticas assistencialistas, por parte do Estado, incutindo um ambiente de stand by, por parte dos indígenas. O que pode ser observado na seguinte fala:

O assistencialismo trouxe muita acomodação [...] precisa distinguir o assistencialismo dos direitos sociais, dos direitos políticos, [...] dos " $n$ " direitos que o indígena tem e, que hoje, nós "brigamos" aqui no município (de Campo Grande MS). A gente tenta fazer com que as políticas afirmativas aconteçam nas comunidades e isso não tem acontecido (CANDELÁRIA, 2017).

Um exemplo dessa acomodação, de acordo com Elisângela, é a dificuldade de reunir as mulheres indígena para o levantamento de suas demandas emergenciais que visam, em especial, o acesso à saúde e à programas de geração de renda, por exemplo, Elisângela compara, ainda, a maior facilidade acesso, à esses serviços, por indígenas em contexto urbano do que as indígenas residentes nas aldeias e, ainda assim, há dificuldades em "deixar o assistencialismo de lado, de deixar a tutela, de deixar esse sistema paternal que enredou o nosso povo" (CANDELÁRIA, 2017). Elisângela exemplifica esse sistema mencionando o modelo de "troca", quando a mulher indígena participa de dada ação afirmativa mediante a troca por algo que lhes chamem a atenção. "Elas não dão muito valor sem troca" (CANDELÁRIA, 2017), como mais uma consequência da intervenção do não-índio no ethos dos indígenas ocasionando a perda de sua identidade. "Somos índios? Nós não estamos na aldeia, nós deixamos de ser índios, né? Não, nós não deixamos de ser índios”. E, dessa forma, fica incumbido aos indígenas inseridos no poder público a transformação da realidade de seu povo, mediante a elaboração de políticas públicas e ações afirmativas específicas.

Isto, quando há a oportunidade de estarem inseridos, pois, como assevera Elisângela, "quando encontramos algum gestor que reconhece e quer fazer, ele também encontra dificuldade entre os seus aliados" (CANDELÁRIA, 2017). O que, por sua vez, não tem sido um obstáculo para a luta do movimento indígena por igualdade de direitos e de oportunidades porque, segundo a entrevistada, é por meio do "diálogo e do conhecimento é que nós vamos conseguir ter o acesso as políticas públicas e também acesso aos direitos que nos é...que nos é dado [...] Nós estamos aqui em Campo Grande, nós somos responsabilidade do município"(CANDELÁRIA, 2017). Dessa forma, 
[...] nós não queremos criar um subsistema na cidade, nós queremos apenas uma saúde de qualidade, uma educação de qualidade, o acesso, né, das nossas crianças, das nossas mulheres - que a maioria delas ainda são analfabetas, mal sabem assinar o nome e através de algumas políticas públicas positivas elas tem [...] tentado fazer cursinho a noite pra..pra aprender a ler, pra ajudar o filho, pra ter uma vida diferenciada, é qualidade de vida, né?Então esse é o sonho da mulher urbana e é um sonho também que eu tive, que tô realizando aos poucos. (CANDELÁRIA, 2017).

A problemática ineficácia das políticas públicas para os povos indígenas está envolta ao fato de que tais "políticas públicas não são pautadas pelos indígenas, não são pautadas." (CANDELÁRIA, 2017). Sendo "raro quando se vai ouvir um indígena, entendeu? Mesmo porque, as nossas lideranças [...] quando se vai colocar alguém no espaço público, [...] eles não estão preparados, assim, pra apontar [alguém para ocupar esses espaços]" (CANDELÁRIA, 2017). Esse despreparo mencionado é reflexo do machismo intrínseco dentro da cultura indígena e essa observação pode ser feita por meio da seguinte fala "eles querem sempre um homem, né? Não importa a qualificação, não importa se ele está preparado para aquele cargo ou não. Então, isso tem atrasado também" (CANDELÁRIA, 2017) de certo modo a inserção das mulheres indígenas nas agências de poder e a efetividade das políticas públicas. O que denota aos resquícios da tutela indígena e não culpa dos mesmos, haja vista que:

[...] as nossas lideranças, a maioria delas, também não tem esse conhecimento [...]. Esse conhecimento concreto da política pública entendeu? [...] eles querem as coisas pra ontem, eles não sabem que eles não conhecem ainda a burocracia, entendeu? Eles não conhecem a burocracia do papel, dos tramites, então eles não conhecem. E quando você chega lá, eles querem que seja assim: num piscar de olhos. E, isso, isso tem atrasado um pouco a nossa política, porque quem faz tudo são os purutuias. São os purutuias ainda, é eles que pautam as políticas, são eles que escrevem os projetos, são eles que apresentam, [...] (CANDELÁRIA, 2017).

Somado a isso Elisângela relata que a falta de conhecimento em relação a realidade e cultura indígena, por parte dos representantes políticos, tem contribuído para que os programas continuem voltados ao assistencialismo. Assim como, para mostrar à população um governo inclusivo que pauta políticas públicas para todas(os) independente de raça, etnia, religião, orientação sexual, entre outros. Quando o que se observa são pessoas desqualificadas ocupando cargos, que deveriam ser ocupados por quem, de fato, detém conhecimentos em relação à pauta. Elisângela afirma que:

Quando tem um índio que conhece um pouquinho mais, que levanta a voz, que não aceita, que vai pro debate, que fala que não é daquele jeito, [...] os gestores também não querem um índio [com essas características]. Eles querem aquele indinho que fica lá, bonitinho, caracterizado pra posar na foto, sabe? [...] isso entristece, porque você vai, você busca se qualificar, você estuda, vai atrás, coloca seus pensamentos, 
os seus ideais na mesa. Mas, é não tem, não influencia, não influencia. [...] isso hoje, em pleno século XXI, é inadmissível [...] e quando eu coloco as minhas ideias..é..ainda sou muito criticada pelas lideranças, sofro muitas criticas das lideranças. Mas assim, eu sempre tento me impor, eu to aqui e pronto, entendeu? (Candelária, 2017).

Ou seja, há um processo de empoderamento de algumas mulheres indígenas, que objetivam disseminar o conhecimento acerca dos direitos das mulheres e dos direitos indígenas dentro de suas comunidades, a fim de que suas vozes sejam ampliadas. Elisângela afirma que os homens das comunidades "sabem que as mulheres são capazes, [...] eles tem medo que as mulheres [...] acabem ocupando, né, o espaço de liderança deles e aí eles fecham o grupo, entendeu? [...] Te exclui. (Candelária, 2017)”. Como exemplo, cita que enfrentou o machismo nos conselhos, nas assembleias e reuniões, tendo que provar a todo instante que podia estar naquele espaço dialogando juntamente com outras lideranças, mostrando que poderia "pautar as políticas públicas, que eu conhecia, que eu sabia o que estava falando porque eu vivi na pele, porque eu fui mãe, porque eu fui moradora de aldeia [...]. Então, hoje eles me respeitam como tal" (CANDELÁRIA, 2017).

A inserção das indígenas nos espaços de poder é baseada na troca, a mesma na qual Elisângela menciona quando faz referência à dificuldade na realização de atividades com as mulheres indígenas. Isto é, a relação de troca está naturalizada na sociedade como um todo. Ainda assim, a entrevistada, menciona que quando os brancos "querem usar a figura indígena, sabe? [...] eles chamam, mostram o projeto "preciso de você, preciso do aval do conselho pra eu poder atuar dentro das comunidades, se você não me ajudar, eu não ou conseguir" (Candelária, 2017). A contrapartida que "eu peço sempre é a inserção de indígenas no grupo profissional, né? Na equipe técnica. ”E embora seja mediante troca de interesses, representa pequenos avanços e conquistas.

A fim de que haja a continuidade dos ganhos para povos indígenas é necessário, de acordo com Elisângela Candelária, a qualificação com qualidade. A entrevista faz a seguinte indagação: "Por que será que nós indígenas não somos aprovados em concursos públicos?" Partindo do pressuposto que, em um concurso público o indivíduo concorre por meio de uma prova e o que contará para sua efetivação no cargo almejado é sua média final. "Então, tem alguma coisa aí que está faltando, [...] nos melhores cargos, não tem indígena. Tem indígena de motorista, tem indígena de porteiro, tem indígena na recepção. Mas, os cargos mais elevados [...], nós não temos.” (Candelária, 2017). Isso é resultado, segundo Elisângela, de um sistema feito por brancos no qual estes ditam as regras e limites para os povos indígenas. 


\section{Considerações finais}

A visão monolítica colabora com a exclusão invisibilizando a rede de contato e agência que o ser indígena estabelece com a sociedade exterior/envolvente. Considerou-se assim, nesta pesquisa, pertinente atribuir à ação política e à culturalidade indígena, uma visão do agente no trânsito da sociedade, reafirmando sua interculturalidade, como um dado da sua ação intersubjetiva. Colaborando para o seu legado de conquistas em espaços políticos, com base numa cosmovisão própria que transforma os espaços étnicos e institucionais.

Portanto, aqui, buscou se desmistificar o pensamento leigo de que os indígenas são povos apáticos, sem história e sem perspectivas de ação efetiva frente à busca por seus direitos. Ou que tais ações são tuteladas, agenciadas ou dependentes de agentes externos por incapacidade de ação própria. Ou ainda, pela imagem de distanciamento, ingenuidade ou desconhecimento das regras sociais e políticas, ou falta de conhecimento das estruturas sociais não indígenas. Mediante a evidenciação das estratégias de sobrevivência e agenciamento político dos povos indígenas, sob a perspectiva da mulher Terena. De modo que, a estabelecer a discussão no tocante à inserção da mulher indígena em espaços institucionais, oportunizado pela migração aos centros urbanos.

Entendendo de antemão que, por pertencer ao gênero feminino a mulher se encontra em situação de vulnerabilidade e ser indígena significa que seus direitos são ignorados. Infere que, ser uma mulher indígena significa permanecer constantemente em déficit na luta pela garantia de seus direitos e pela equidade de oportunidades. Acerca disso, as mulheres indígenas têm sofrido em seu percurso histórico opressões diversas, vivenciadas tanto nas reservas indígenas quanto em contexto urbano, como consequência do contato com a sociedade ocidental. São, portanto, oprimidas nos âmbitos público e privado. E embora haja o processo de empoderamento de algumas mulheres dentro de suas aldeias e comunidades, inspiradas por outras lideranças como foi Enir Bezerra da Silva, são poucas as mulheres que, de fato, se empoderaram.

Ainda assim, por meio da perspectiva etnográfica da Antropologia Feminista, contida na presente pesquisa, foi possível vislumbrar os efeitos e os simbolismos dos valores de gênero na sociedade indígena à luz de suas práticas políticas.

Possibilitando, desse modo, compreender quais são e como as indígenas lidam com as opressões vivenciadas. Bem como, na verificação da estratégia de inserção da mulher Terena nos espaços de poder, no município de Campo Grande - MS, que perpassam pelo fator da migração e o que esta provoca no cotidiano da indígena urbana. O processo de inserção das 
mulheres indígenas dentro das agências de ações públicas apresenta as mesmas barreiras vivenciadas pelas demais mulheres. Obstáculos construídos pelo sistema patriarcal, ocasionando desigualdades e inequidade de gênero. Contudo, ser indígena adiciona a esses fatores um ( pré)conceito a mais, de forma que essas se sentem mais exigidas e encontram maiores barreiras comparadas às mulheres brancas e negras.

A antropologia feminista analisa a organização social pautada na relação entre gênero e poder. O que procurei desenvolver aqui foram as estratégias de ações tanto de sobrevivência, pautadas na resistência e luta das mulheres indígenas, quanto de inserção política, sob a perspectiva da mulher Terena. O resultado demonstrou que, ao contrário do imaginário ocidental, os povos indígenas em contato com o não índio, possuem perspectivas estratégicas no tocante a inserção política. O contato com a sociedade ocidental que traz dor às mulheres indígenas é o mesmo que possibilitou o diálogo e incitou o uso da moeda de troca para a inserção política. Na busca da compreensão do que se faz necessário para a alternância da realidade social dos povos originários, se constatou que a ineficácia das políticas públicas e ações afirmativas ocorrem por dois motivos principais: por um lado, pelo não conhecimento da funcionalidade das instituições públicas e sua burocracia por parte de lideranças indígenas que estão acostumadas com o assistencialismo de governantes políticos. Por outro lado, pelo machismo intrínseco na sociedade indígena na qual mais importante do que a figura da mulher capacitada, com conhecimento técnico e das especificidades de seu povo, é a presença, simples e pura, do homem.

Em meio a isso, há um levante de mulheres indígenas empoderadas na busca por seus espaços de direito, o de se inserir no espaço de poder, portanto um simbolismo de resistência. Pois, é uma mulher e índia lutando para se inserir e pautar políticas em um espaço criado por e para homens. É uma mulher indígena na busca da superação de toda forma de preconceito e discriminação vivenciada, principalmente, por meio da execução e construção efetiva de Políticas Públicas para os povos indígenas.

\section{Referências}

COMISSÃO PRÓ-ÍNDIO. A cidade como local de afirmação dos direitos humanos. São Luiz/MA: Gaspar Garcia de Direitos Humanos. v.1, mai 2013. Disponível em: <http://www.eng2016.agb.org.br/resources/anais/7/1468173844_ARQUIVO_Artigo-FinalENG.pdf http://www.cpisp.org.br/pdf/IndiosnaCidade.pdf>. Acesso em: 10 mai. 2017.

BEAUVOIR, Simone de. O segundo sexo 1: fatos e mitos. . Rio de Janeiro: Nova Fronteira, 1980. 311p. 
BONETTI, Alinne de Lima. Etnografia, gênero e poder: antropologia feminista em ação. Mediações, Londrina, v.14, n.2, p. 105-122, dez. 2009. Disponível em: < http://www.uel.br/revistas/uel/index.php/mediacoes/article/view/4509 >. Acesso em 10 mai. 2017.

DE PAULA, Roberto de Paula; VIANNA, Fernando de Luiz Brito. Mapeando Políticas Públicas para Povos Indígenas. Rio de Janeiro: Contra Capa Livraria; LACED/Museu Nacional/UFRJ, 2011. 116p.

HALL, Stuart. A Identidade Cultural na pósmodernidade. RJ: Editora DP\&A, 2005.

IBGE.Instituto Brasileiro de Geografia e Estatística. Disponível em:<http://indigenas.ibge.gov.br/>. Acesso em: 12 jun. 2017.

- Instituto Brasileiro de Geografia e Estatística. Disponível em <http://cidades.ibge.gov.br/xtras/perfil.php?codmun=500270>. Acesso em: 12 jun. 2017.

LASMAR, Cristiane. Mulheres indígenas: representações. Revista Estudos Feministas, v. 7, n. 1 e $2,1999$.

MELO, Juliana G. Dimensões do Urbano: O que as narrativas indígenas revelam sobre a cidade? Considerações dos Baré sobre Manaus, AM. In:Teoria e Controle, Juiz de Fora, v.8, n. 1, p. 115 a 126, jun. 2013. Disponível em: <http://repositorio.ufrn.br:8080/jspui/bitstream/123456789/18708/1/Dimens\%C3\%B5es_Julia na.pdf >. Acesso em: 10 mai. 2017.

MURARO, Rose Marie; PUPPIN, Andrea Brandão. Mulher, gênero e sociedade. Rio de Janeiro: Reúne Dumará, 2001. 173p.

NUNES, Eduardo Soares. Aldeias urbanas ou cidades indígenas? Reflexões sobre índios e cidades. Espaço Ameríndio, Porto Alegre, v.4, n.1, p. 9-30, jun. 2010.

OLIVEIRA FILHO, João Pacheco de. Ensaios em antropologia história. Rio de Janeiro: Editora UFRJ, 1999, 272p.

ORTNER, Sherry B. Making Gender: the politics and erotics of culture. Boston: Beacon Press, 1966.

PINTO,Alejandra Aguilar. Reinventando o feminismo: as mulheres indígenas e suas demandas de gênero. In: Fazendo Gênero 9 Diásporas, Diversidades e Deslocamentos, Florianópolis, aAgo 2010. Disponível em: <http://www.fazendogenero.ufsc.br/9/resources/anais/1276200140_ARQUIVO_ApresentFaz endoGeneroAleword.pdf >. Acesso em: 10 mai. 2017.

RUBIN, Gayle. O tráfico de mulheres. Notas sobre a "Economia Política" do sexo. Tradução de Christine Rufino Dabat. Recife: SOS Corpo, 1993.

SACCHI, Ângela; GRAMKOW, Márcia Maria. (Orgs.). Gênero e povos indígenas: coletânea de textos produzidos para o "Fazendo Gênero 9" e para a "27 Reunião Brasileira de Antropologia". - Rio de Janeiro, Brasília: Museu do Índio/ GIZ / FUNAI, 2012. 
SAFFIOTI, Heleieth Iara Bongiovani. A mulher na sociedade de classe: mito e realidade. Petropolis, RJ: Vozes, 1976. 383p.

SCOTT, Joan. Gender: a useful category of historical analyses. Gender and the politics of history. New York, Columbia University Press. 1989. Tradução: Christine Rufino Dabat e Maria Betânia Ávila.

SILVA, Enir Bezerra da. Onde já se viu, na cultura indígena, uma mulher ser cacique?. Ministério Público Federal. Disponível em: <http://www.prms.mpf.mp.br/servicos/sala-deimprensa/noticias/2015/04/ENIR.pdf>. Ministério Público Federal. Enir Bezerra da Silva: onde já se viu, na cultura indígena, uma mulher ser cacique?. Acesso em: 12 jun. 2017.

SILVA, Luiz Felipe Barros da; BERNADELLI, Mara Lúcia Falconi da Horta. SILVA e, 2016 A Constituição da comunidade urbana água bonita em Campo Grande/MS: territorialidade e identidade indígena. In: XVIII encontro nacional de geógrafos, n. 18, 2016 .

STRATHERN, Marilyn. Uma relação incômoda: o caso do feminismo e da antropologia. In: Mediações, Londrina, v.14, n.2, p. 105-122, dez.2009. Disponível em: $\langle$ http://www.uel.br/revistas/uel/index.php/mediacoes/article/view/4508 >. Acesso em: 10 mai. 2017.

VERDUM, Ricardo (organizador). Mulheres Indígenas, Direitos e Políticas Públicas/ Ela Wiecko. V. de Castilho .... [et al]. - Brasília: Inesc, 2008. 